XVIII.-Contributions to our Knowledge of the Aconite Alkaloïds. Part IX. The Effect of Heat on Aconitine and some of its Derivatives. Formation of Pyraconitine.

By Wrndham R. Dunstan, M.A., F.R.S., and Francis H. Carr, Assistant Demonstrator in the Research Laboratory of the Pharmaceutical Society.

Is Part I of these contributions, the observation was recorded that when aconitine is heated at its melting point, $188-189^{\circ}$, a volatile compound escapes, the alkaloïd losing about 10 per cent. in weight. At first it was conjectured that this might be due to the loss of benzoic anhydride and the formation of aconine. Further investigation has shown, howerer, that the decomposition is of a wholly 
different kind, and that a new alkaloid is produced which, having regard to its mode of origin, we propose to name pyraconitine.

By heating in a paraffin bath a weighed quantity of pure aconitine at its melting point $\left(189-190^{\circ}\right)$, the alkaloild being contained in a small bulb-tube, having a small U-tabe sealed on so as to act as a condenser, it was ascertained that acetic acid distilled over. By conducting the last stage of this operation in a slow current of air, it was proved, by titrating the distillate with standard alkali, that $9 \cdot 28$ per cent. of the acid is given off from the alkaloïd the loss, determined by weighing the residue, is represented by almost the same percentage, namely 9.96 ; weight of aconitine, 1.5079 ; weight of residue, $1.3577=9.96$ per cent. The loss of 1 molecular proportion of acetic acid by 1 molecular proportion of aconitine corresponds with 9.27 per cent., a number which is in close agreement with the experi. mental results. A minute quantity of benzoic acid also passes over, but the amount is almost inappreciable if the temperature is not allowed to rise during the experiment. The identity of the acetic acid was conclusively proved by converting it into the silver salt and submitting this to analysis. Silver salt, $0 \cdot 1722$ gram; silver, $0 \cdot 1112$ gram $=64.58$ per cent. Calculated for silver acetate, 64.66 per cent.

The production of acetic acid from aconitine was not to be inferred from previous knowledge of the properties of this alkaloïd. Wright has stated that benzoic acid is the only acid formed when aconitine is hydrolysed. This benzoic acid which so readily separates on hydrolysis is not detached from aconitine when it is heated at its melting point. There is no doubt that aconitine contains one benzoyl group, and that the acetic acid is derived from an acetyl group. Further investigation has shown that aconitine must be regarded as acetylbenzoylaconine, and our so-called "isaconitine" as benzoylaconine; for we shall prove in our next paper that one molecular proportion of acetic acid separates when the one alkaloïd changes into the other, and also when aconitine is hydrolysed.

\section{Composition and Properties of Pyraconitine.}

The dark-coloured alkaloïdal residue remaining after the distillation was dissolved in dilute sulphuric acid and the solution fitered; dilute ammonia was then added in slight excess, and the liquid extracted several times with ether. The alkaloïd was removed from the ethereal solution by shaking it with very dilute hydrobromic acid, and the acid liquid precipitated in fractions by the addition of dilute ammonia in order to remove the brown colouring matter, which 
accumulated in the first and second precipitates; excess of ammonia was then added to the colourless solution, and the alkaloïd extracted with ether. When the dry ethereal solution was spontaneously evaporated, it left a varnish-like residue of base which refused to crystallise; it was therefore dissolved in dilute hydrobromic acid, and the neutral liquid slowly evaporated in a desiccator. No crystalline salt separated. The dry residue was next dissolved in absolute alcohol, and the clear solution mixed with anbydrous ether until it became slightly turbid. The small, white crystals of the hydrobromide which separated from this mixture melted at $280^{\circ}$, and still melted at the same temperatnre after recrystallisation. On adding soda in slight excess to the solution of the pure salt, and extracting with ether, white slender needles (m. p. 167.5 ${ }^{\circ}$ corr.) of the base were ohtained by the slow evaporation of the ethereal solution. The crystals are sparingly soluble in water, but readily in alcnbol. chloroform, and ether. The aqueous solution is slightly bitter, but with a somewhat burning after-taste. The solution in anhydrons alcohol is without action on polarised light; although some specinens examined, probably not quite pure, exerted a feeble dextrorotation, and others a feeble lævorotation. The base readily dissolves in acids. forming salts which are difficult to obtain well crystallised from an aquenus solution. but separate in well-defined crystals from solution in a mixture of anbydrous alcohol and ether.

Pyraconitine hydrobromide $\mathrm{C}_{31} \mathrm{H}_{41} \mathrm{NO}_{10}, \mathrm{HBr}$ separates in anhydrous crystals from a mixture of alcohol and ether, and melts at $280^{\circ}$ (corr.). It is soluble in water and in alcohol.

0.2289 of salt gave $0.0624 \mathrm{AgBr} . \mathrm{Br}=11 \cdot 6$. $\mathrm{C}_{31} \mathrm{H}_{41} \mathrm{NO}_{10} \mathrm{HBr}$ requires $\mathrm{Br}=11.97$ per cent.

On some occasions crystals of this salt, possibly hydra ed.t have been obtained, melting at $204^{\circ}$. When burned in a stream of oxygen, the salt furnished the following data.

$0 \cdot 1452$ gave $0.2975 \mathrm{CO}_{2}$ and $0 \cdot 08349 \mathrm{H}_{2} \mathrm{O} . \quad \mathrm{C}=55 \cdot 87 ; \mathrm{H}=6.38$. $0.1314,0.2685,, \quad, 0.0731 \quad, \quad \mathrm{C}=55.72 ; \mathrm{H}=6.18$. Calculated for $\mathrm{C}_{31} \mathrm{H}_{41} \mathrm{NO}_{10}, \mathrm{HBr}$. $\mathrm{C}=55.69 ; \mathrm{H}=6.28$ per cent.

$$
" \quad " \mathrm{C}_{31} \mathrm{H}_{99} \mathrm{NO}_{1 \mathrm{n}} \mathrm{HBr} . \mathrm{C}=55.85 ; \mathrm{H}=6.0 \quad \text {, }
$$

Of the two probable formulæ for aconitine (Part I), namely, $\mathrm{C}_{33} \mathrm{H}_{43} \mathrm{NO}_{12}$ and $\mathrm{C}_{33} \mathrm{H}_{45} \mathrm{NO}_{12}$, these analyses agree hetter, perhaps, with the formula for pyraconitine derived from $\mathrm{C}_{31} \mathrm{H}_{99} \mathrm{NO}_{10}$. However, until more decisive evidence has been obtained on this point we shall retain the formula $\mathrm{C}_{31} \mathrm{H}_{11} \mathrm{NO}_{10}$.

The equation representing the production of pyraconitine from aconitine is therefore 
ON ACONITINE AND SOME OF ITS DERIVATIVES.

$$
\underset{\text { Aconitine. }}{\mathrm{C}_{33} \mathrm{H}_{45} \mathrm{NO}_{12}}=\underset{\text { Acetic acid. }}{\mathrm{C}_{2} \mathrm{H}_{4} \mathrm{O}_{2}}+\underset{\text { Pyraconitine. }}{\mathrm{C}_{31} \mathrm{H}_{41} \mathrm{NO}_{10}}
$$

Pyraconitine hydrobromide is levorotatory. A determination of this specific rotation in aqueous solution gave the following result.

whence

$$
\alpha\left[15^{\circ}\right]=-2^{\circ} ; l=2 \mathrm{dcm} \text {; } c=2 \cdot 1364,
$$

$$
\frac{2 \times 100}{2 \times 2.1368}=[\alpha]_{\mathrm{D}}=-46.8^{\circ} \text {. }
$$

Pyracomitine hydrochloride, $\mathrm{C}_{31} \mathrm{H}_{41} \mathrm{NO}_{1,0} \mathrm{HCl}$, crystallises in rosettes from a mixture of alcohol and ether. It melts at $248.75^{\circ}$ (corr.).

Pyraconitine hydriodide, $\mathrm{C}_{31} \mathrm{H}_{41} \mathrm{NO}_{10}, \mathrm{HI}$, also crystallises from a mixture of alcohol and ether in colourless rosettes, which are apt to become yellowish on standing. They melt sharply at $220.5^{\circ}$ (corr.), and can be crystallised (in prisms) from aqueous solution more readily than the hydrochloride or hydrobromide.

The salts of pyraconitine are somewhat bitter, and are apparently not toxic in small doses. The exact physiological action of this alkaloïd is being investigated by Professor Cash, F.R.S.

Pyraconitine aurichloride, $\mathrm{C}_{31} \mathrm{H}_{41} \mathrm{NO}_{10}, \mathrm{HAuCl}_{4}$, is thrown down as a pale yellow precipitate, when auric chloride is added to a solution of the hydrochloride; all attempts to crystallise this salt have hitherto failed. Experiments have been made with the view of preparing an anrichlor-derivative from it similar to that producible in the case of isaconitine, but the pyraconitine compond exhibits no tendency to form such a derivative.

\section{Hydrolysis of Pyraconitine.}

Pyraconitine and its salts readily undergo hydrolysis when heated with water and acids, or when allowed to remain in contact with fixed alkalis. When soda is added to an aqueous solution of a salt of pyraconitine, the alkaloïd is thrown down in white flocks, which gradually dissolve if excess of alkali is added, owing to the rapidity with which hydrolysis occurs; nothing is obtained from the solution on distillation, but ether extracts from it an alkaloïd pyraconine, which remains as an uncrystallisable varnish when the ether is evaporated. The residual alkaline solution furnishes benzoic acid when acidified, but no other acid product; by estimating this, it has been found that the benzoic acid produced amounts to 17.91 per cent. of the pyraconitine. The amount calculated from the equation

$$
\underset{\text { P5raconitine. }}{\mathrm{C}_{31} \mathrm{H}_{41} \mathrm{NO}_{10}}+\mathrm{H}_{2} \mathrm{O}=\underset{\text { Benzoic acid. }}{\mathrm{C}_{7} \mathrm{H}_{6} \mathrm{O}_{2}}+\underset{\text { Pyraconine. }}{\mathrm{C}_{24} \mathrm{H}_{37} \mathrm{NO}_{9}}
$$

is 18.26 per cent. It therefore appears that the benzoyl group of aconitine is present in pyraconitine, which, like aconitine, undergoes voL. LXV. 
hydrolysis, losing its benzoyl group as benzoic acid, and furnishing a new base which it will be convenient, following the analogy of aconitine, to name pyraconine.

\section{Composition and Properties of Pyraconine.}

Pyraconine is an amorphous base resembling aconine in its properties. It is readily soluble in water and also in ether : in the latter respect it differs from aconine. The aqueous solution has a somewhat sweet taste, and is lævorotatory. A determination of the specific rotation gave the following data.

whence

$$
\alpha\left[15^{\circ}\right]=-2 \cdot 04^{\circ} ; l=2 \mathrm{dcm} . ; c=1 \cdot 121,
$$

$$
\frac{2.04 \times 100}{1.121 \times 2}=[\alpha]_{\mathrm{D}}=-90.99^{\circ} \text {. }
$$

Pyraconine combines with acids, forming salts which are very soluble in water. They crystallise more or less readily from their aqueous solutions, but are more easily obtained in well-defincd crystals from a mixture of alcohol and ether.

Pyraconine hydrochloride, $\mathrm{C}_{24} \mathrm{H}_{3 i} \mathrm{NO}_{9}, \mathrm{HCl}$, crystallises in cubes with $1 \mathrm{H}_{2} \mathrm{O}$, which is lost at $100^{\circ}$. They melt at $154^{\circ}$ (corr.), and are very soluble both in alcohol and in water. The aqueous solution is lævorotatory. In determining the specific rotation the following results were obtained.

whence

$$
\begin{gathered}
\alpha\left[15^{\circ}\right]=-4.4^{\circ} ; l=2 \mathrm{dcm} . ; c=1.9595, \\
\frac{100 \times 4.4}{1.9595 \times 2}=[x]_{\mathrm{D}}=-102.07 .
\end{gathered}
$$

Unlike aconitine, isaconitine, and aconine, the specific rotation of pyraconine and its salts have the same sign, both are lævorotatory.

This salt was burned for the determination of the carbon and hydrogen, and the water and chlorine were also estimated, with the following results.

0.1266 gave $0.2462 \mathrm{CO}_{2}$ and $0.0881 \mathrm{H}_{2} \mathrm{O} . \quad \mathrm{C}=53.03 ; \mathrm{H}=7.73$.

$0.1097,0.2154, \#, 0.078,, \quad \mathrm{C}=53.55$; H $=7.9$.

0.2924 lost 0.0087 of water. $\mathrm{H}_{2} \mathrm{O}=2.97$.

0.2837 gave $0.0756 \mathrm{AgCl} . \quad \mathrm{Cl}=6.57$.

$\mathrm{C}_{24} \mathrm{H}_{37} \mathrm{NO}_{9}, \mathrm{HCl}, \mathrm{H}_{2} \mathrm{O}$ requires $\mathrm{C}=53.59 ; \mathrm{H}=7 \cdot 44 ; \mathrm{H}_{2} \mathrm{O}=3 \cdot 37$;

$$
\mathrm{Cl}=6.58 \text { per cent. }
$$

Pyraconine aurichloride, $\mathrm{C}_{24} \mathrm{H}_{37} \mathrm{NO}_{9}, \mathrm{HAuCl}_{4}$, is thrown down as a yellow, amorphous precipitate, which quickly aggregates to a sticky mass, when auric chloride is added to a strong solution of pyraconine hydrochloride. If this salt crystallises at all, it does so only with great difficulty. Crystals have only once been obtained, and then 
not in quantity sufficient to enable us to ascertain that they consisted of the aurichloride. As a rule, it separates from solvents as an oil.

From the observations recorded in the foregoing account, it will be seen that pyraconitine bears little resemblance to aconitine, but exhibits some affinities with isaconitine; the salts of pyraconitine, however, melt as a rule at lower temperatures, and show greater rotatorypower, than those of isaconitine. Moreover, pyraconitine does not possess the peculiar property of forming an aurichlor-derivative so characteristic of isaconitine.

Pyraconine, the product of the hydrolysis of pyraconitine, somewhat closely resembles aconine, the hydrolytic product of both aconitine and isaconitine. It differs from aconine, however, in several respects, notably in its rotatory power, and that of its salts, as well as in its solubility in ether.

Action of Heat on Aconitine Salts.-We find that the salts of aconitine, like aconitine itself, lose acetic acid when they are heated at about $190^{\circ}$. The acetate of aconitine requires rather a higher temperature for its decomposition, acetic acid not being evolved until the salt has been heated to a temperature of nearly $198^{\circ}$.

Action of Heat on Isaconitine.-Haring fully made out the mode of action of heat on aconitine, it became of considerable interest to ascertain how far isaconitine resembled it in this respect. About 1 gram of the pure colourless amorphous base was gradually heated in a paraffin bath. At $115^{\circ}$, the alkaloïd fused to a clear liquid, which underwent nothing more than a darkening in colour on raising the temperature to about $200^{\circ}$; slightly above this decomposition set in, attended with effervescence, and a colourless liquid distilled, consisting chiefly of water; no acetic acid was obtained, in fact, the distillate was not acid to test-paper. A further important constitutional difference between aconitine and isaconitine is thus bronght to light, which is explained by the results recorded in a subsequent paper.

Action of Heat on Aconine.-As the usual formula of aconine, $\mathrm{C}_{26} \mathrm{H}_{41} \mathrm{NO}_{11}$, differs from that of pyraconine, $\mathrm{C}_{24} \mathrm{H}_{37} \mathrm{NO}_{9}$, by the elements of acetic acid, $\mathrm{C}_{2} \mathrm{H}_{4} \mathrm{O}_{2}$, and, moreover, as, according to Wright, only aconine and benzoic acid are obtained by the hydrolysis of aconitine, aconine when heated should lose acetic acid and farnish pyraconine, for we have shown that aconitine when heated loses acetic acid forming pyraconitine, which, on hydrolysis, loses benzoic acid pronucing pyraconine. When pure dry aconine is gradually heated in a paraffin bath, it fuses to a clear liquid at $120^{\circ}$; as soon as the temperature has risen to $190^{\circ}$, the liquid darkens, and at a somewhat higher temperature begins to effervesce, the vapours evolved 
condensing in the receiver to a colourless liquid. On examination, this was fonnd to be chiefly water; no acetic acid was present, the liquid not being acid to test-paper. By weighing the dark-coloured residue of alkaloïd it was ascertained that the aconine had lost nearly 10 per cent. in weight; this residue, when heated at about $250^{\circ}$, decomposed completely. The fact that aconine does not give acetic: acid on heating points to the conclusion that this acid must have been split off in its formation from aconitine. We have shown in previous communications that both aconitine and isaconitine undergo hydrolysis, aconine being the basic product in each case. In a subsequent paper we show that when aconitine passes into isaconitine, it loses acetic acid. Synthetical experiments are being made to test the accuracy of this new view of the constitution of "aconitine" and " isaconitine," which would represent pyraconitine as the anhydroderivative of the latter alkaloid.

Research Laboratory,

Pharmaceutical Society, London. 